\title{
Why don't they want to know?
}

\author{
S Hancocks, OBE*
}

\author{
Like a colleague at a recent seminar said when we were chatting \\ over coffee, 'it's not a question of feeling undervalued, it is more a \\ frustration that patients don't seem to want to share our enthusiasm \\ for the finer points of dentistry.' He went on...
}

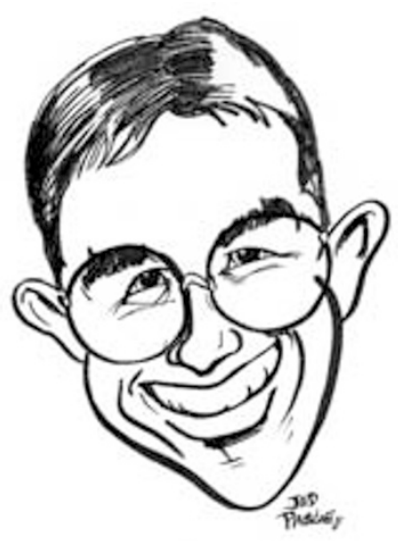

Why is it that patients can't see it? The point surely is that you've spent five years training, and then all the time in-between practising and perfecting what you are doing for their teeth, and yet they don't seem in the least bit interested in what you do in their mouths.

They'd be interested enough if the extra two microns difference between the margin of their crown prep and the crown itself meant that it was sensitive to hot and cold. Oh yes, that would be a different matter entirely. Then they'd soon be back complaining of discomfort around 'that crown that you fitted last week'.

But fit the crown to perfection and do they ever come back and mention it? Not a bit of it. In fact if they comment at all it's much more likely to be to the effect that 'soand-so at the office said how nice it looked'. Yeah, right, like from a distance of how many feet away? So, 'so-and-so' could judge the benefit of a $50^{\circ}$ taper on the labial surface of the prep from across a desk? I don't think so!

Well, yes, of course, satisfying that they thought it looked good but that's hardly the point of four years of undergraduate classes in restorative dentistry is it? Anyway, where was I?

Oh yes, margins. Mind you, while I'm on the subject it doesn't end there does it? Take the difference between amalgam and composite as another example. You patiently explain the relative advantages and disadvantages in terms of load values, wear abrasion, creep potential and durability and what's the first question they ask? 'So what does it cost?'

Just the same with wisdom teeth. Do you find that too? You do all that 'what seems to be the problem? Let's have a look then, oh yes I see, alright I'll just take an X-ray' stuff and then sit down to tell them that it would be best to take it out because otherwise there'll just be a recurrence of the pericoronitis (yes, OK, soreness around the tooth). Then you carefully detail the risks for and against; recurrent bacteraemia, bruising to the lingual nerve, parasthesia of the inferior dental distribution and so on and so forth, to get meaningful consent, and what do they come up with? 'Will it hurt?'

No questioning of whether or not you could use a broader bladed retractor to try and prevent damage to the lingual nerve, no interrogation about how many times you had to do MOS procedures before you got your BDS. Oh, no. 'Will it hurt?'

My nurse made an amazing comment the other day. I was rabbiting on about patients not turning up on time or some such gripe

\section{You patiently explain} the relative advantages and disadvantages in terms of load values, wear abrasion, creep potential and durability and what's the first question they ask? 'So what does it cost?'

and she said, 'you're lucky they think you're such a nice man.'

Well, yes, it did stop me in my tracks a bit. It's not exactly what you expect on a wet Wednesday afternoon is it? Anyway, I didn't want to let it go at that so I said, 'how do you mean Babs?'

'They keep coming back,' she said, 'because they like you. That's it. If they didn't like you, they wouldn't keep coming.'

'And if they really knew me, as you do' I said back to her, 'then they wouldn't. Is that what you're saying?' She's been with me a long time so I can get away with it. Plus, I said, I'm a bloody good clinician into the bargain. 'Oh that doesn't bother them,'
Babs said, 'how would they know anyway?' I stood there a bit non-plussed, pulling off a pair of gloves while she carried on. 'Look, all they're interested in is getting in and out as quickly as possible with as little discomfort and at the cheapest price. If you're nice while they're in here that's a real bonus. And you are, so that's great but don't expect me to say it again and the next patient's here now anyway.' Well, you could have knocked me over with a feather.

The strange thing is, I was saying as much to a friend, he's in under-writing, all that small print stuff in insurance policies that I never bother reading. 'Well of course they don't care', he said, 'think of it like this, when you're jetting away on holiday, are you really concerned about the way the pilot's flying the plane? You make the assumption that he, or she, is perfectly competent to do the job. Most people choose an airline on price, availability and how pleasant the cabin crew are. Never think about the pilot.'

So I mentioned it to Babs, asked whether she ever thought about what the pilot was doing. She said the same thing, assumed that the pilot must know what he was doing or they wouldn't allow him to fly the thing. Besides, she said, who needs to know what actually happens as long as you get there and back in one piece. It's far more important to know what the movie is, how much leg room you've got, when the food's coming along and whether or not the drinks are free.

Call me old fashioned but I think it's quite different from something that directly affects your health, like dentistry. Ah well, it's the way of the world. One day they'll realise how right we are and until then we'll just have to soldier on pretending that the lighting in reception is really the more important thing. Anyway, where was I? Oh yes, apparently the angle of the chamfer on the box of a class II restoration prepared for an inlay.....

* The author is commissioning editor for the BDJ. 